\title{
$\mathrm{AO} \mathrm{Hook}$ 금속판을 이용한 견봉쇄골 관절 탈구의 치료
}

\author{
울산대학교 의과대학 강릉아산병원 정형외과학교실
}

이기원 · 최영준 · 안형선 · 김정환 · 황재광 · 한희돈 · 김재현 · 주윤석

\section{Treatment of the Acromioclavicular Joint Dislocation Using a AO Hook Plate}

\author{
Ki-Won Lee, M.D., Young-Joon Choi, M.D., Hyung-Sun Ahn, M.D., Chung-Hwan Kim, M.D., \\ Jae-Kwang Hwang, M.D., Hee-Don Han, M.D., Jae-Hyoun Kim, M.D., Youn-Suk, Joo, M.D. \\ Department of Orthopedic Surgery, Gangneung Asan Hospital, University of Ulsan College of Medicine
}

Purpose: We wanted to evaluate the results of treating acromioclavicular joint dislocation using an AO hook plate.

Materials and Methods: Between February 2008 and September 2009, 10 patients underwent implant removal after surgical treatment of acromioclavicular joint dislocation using a AO hook plate. The Constant-Murley scoring system was administered postoperatively for evaluating the clinical results, and simple X-ray was taken for evaluating the state of reduction.

Results: All cases showed satisfactory results on the clinical and radiological study. The mean ConstantMurley score at follow-up was 90.5 (range: 84 95). Three patients had some degree of discomfort with the hook plate, but these symptoms were relieved on removal of the plate. The radiological evaluation showed restoration of the vertical displacement of the clavicle in all the patients. No complications occurred such as infection, plate failure or redislocation after removal of the plate.

Conclusion: The short term follow-up results of treating acromioclvicular joint dislocation using an AO hook plate were satisfactory both clinically and radiologically.

Key Words: Acromioclvicular joint, Dislocation, AO hook plate

\section{서 론}

견봉쇄골 관절의 탈구는 손상 정도에 따라 보존적 치 료와 수술적 치료를 선택하게 되며, 이의 수술적 치료 에 대해 많은 저자들이 정확한 해부학적 정복과 연부
조직이 충분히 치유될 때까지 견고한 정복의 유지가 중 요하다고 보고하여 왔으나 아직 최적의 술식은 정립되 지 않은 상태이다 ${ }^{2.3 .4}$. 이제까지 많이 사용되는 수술 방 법들로 Modified Phemister technique, Bosworth technique, Weaver-Dunn technique, 비흡수성 대

\footnotetext{
※통신저자: 안 형 선

강원도 강릉시 사천면 방동리 415

강릉아산병원 정형외과

Tel: 033) 610-3240, Fax: 033) 641-8050, E-Mail: hsahn@gnah.co.kr
}

접수일: 2009년 10월 8일, 1차 심사완료일: 2009년 10월 22일, 2차 심사완료일: 2009년 11월 11일, 게재확정일: 2009년 11월 17일 
(band)를 이용하거나 Wolter 금속판을 이용한 수술 등 이 있으며 비교적 최근에 소개된 $\mathrm{AO}$ hook 금속판을 이 용한 수술도 그러한 노력 중 하나이다. 이 금속판은 Wolter 금속판과 달리 견봉하부에 고정하는 갈고리가 없으며, 견봉하부로 들어가는 부분이 상대적으로 납작하 여 비교적 쉽게 견봉하 공간에 위치시킬 수 있어 임상적 적용이 용이하다고 판단된다. 그러나 아직 임상적 효용 에 대한 보고가 그다지 많지 않기에 저자들은 $\mathrm{AO}$ hook 금속판을 이용한 견봉쇄골 관절 탈구의 수술 수기를 소 개하고 그 임상적 유용성에 대하여 알아보고자 하였다.

\section{연구 대상 및 방법}

\section{1. 연구 대상}

2008년 2월부터 2009년 9월까지 AO hook 금속판 을 이용하여 견봉쇄골 관절 탈구를 수술하였던 18예 중 술 후 4 6개월 사이에 내고정물을 제거한 후 4 주 이상
경과된 10예를 대상으로 하였다 (Table 1). 견봉 쇄골 관절 탈구의 분류는 Rockwood 분류 방법 ${ }^{177}$ 을 이용하 였으며 내원 시 쇄골 전후면 방사선 사진을 촬영하여 건측과 비교해 손상 정도를 판정하였다. 수상일로부터 수술일까지의 경과기간은 최단 1 일에서 최장 23 일로 평 균 6.9 일이었으며 추시 기간은 최단 9 개월에서 최장 19 개월로 평균 13.1 개월이었다.

대상환자는 남자가 10 명으로 여자는 없었으며 우측이 5 예, 좌측이 5 예이었다. 연령분포는 최소 35 세에서 최 장 56 세로 평균 45 세였다. 손상 기전으로는 낙상 5 예, 자전거 2 예, 스키손상 1 예, 교통사고 2 예였다.

Rockwood분류는 제 3형이 7예 (70\%), 제 5형이 3 예 $(30 \%)$ 였다. 수술 받은 제 3 형은 육체적 노동 이나 운 동에 종사하거나 외관상 변형을 용납 못하는 환자였다.

\section{2. 수술 기구}

본 연구에 사용된 $\mathrm{AO}$ hook 금속판(LCP Clavicle

Table 1. 10 cases of acromioclavicular joint dislocations which received implant removal

\begin{tabular}{|c|c|c|c|c|c|}
\hline Case No. & Age & Sex & Rockwood Type & Time to surgery(day) & Follow-up period(month) \\
\hline 1 & 39 & M & III & 6 & 15 \\
\hline 2 & 35 & M & III & 2 & 11 \\
\hline 3 & 49 & M & III & 13 & 13 \\
\hline 4 & 43 & M & $\mathrm{V}$ & 2 & 13 \\
\hline 5 & 50 & M & $\mathrm{V}$ & 4 & 9 \\
\hline 6 & 40 & M & III & 17 & 19 \\
\hline 7 & 53 & M & III & 23 & 11 \\
\hline 8 & 38 & M & $\mathrm{V}$ & 1 & 17 \\
\hline 9 & 45 & M & III & 12 & 14 \\
\hline 10 & 56 & M & III & 9 & 9 \\
\hline
\end{tabular}

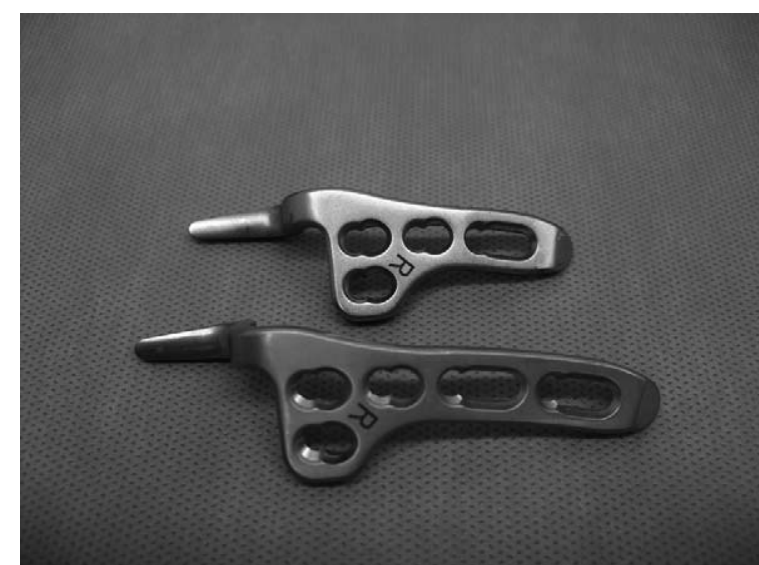

Fig. 1. The AO Hook plate is precontoured $3.5 \mathrm{~mm}$ locking compression plate, made titanium alloy, available in right or left, with 4 through 7 holes that can accept either $3.5 \mathrm{~mm}$ locking, $3.5 \mathrm{~mm}$ cortical or $4.0 \mathrm{~mm}$ cancelous screws. This figure shows plates with 4 or 5 holes.

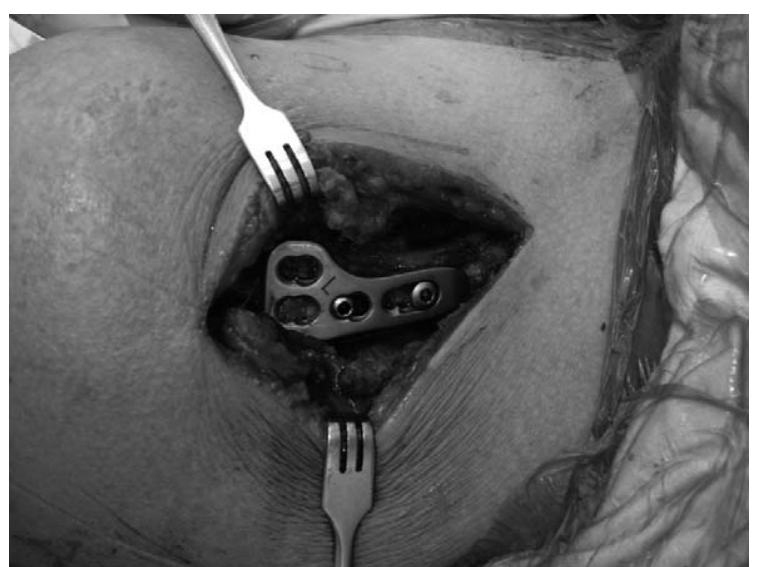

Fig. 2. The photograph shows the intraop-reduction state of acromioclavicular joint dislocation with 4-hole AO hook plate. 
Hook Plate, Synthes ${ }^{\circledR}$, Switzerland) (Fig. 1)은 $3.5 \mathrm{~mm}$ 잠금 압박 나사 (locking compression screw)와 피질골 나사 (cortical screw) 및 $4.0 \mathrm{~mm}$ 해면골 나사 (cancellous screw)를 병용 (LCP combi-hole)할 수 있는 titanium 합금 금속판에 4 개 에서 7개까지 사용 가능한 hole이 있고, 금속판과 견봉 하 공간에 위치하는 부위인 갈고리 사이에는 계단 모양 의 층이 만들어져 있다. 이 층은 $12 \mathrm{~mm}, 15 \mathrm{~mm}, 18$ $\mathrm{mm}$ 의 세 종류의 깊이가 있어서 환자의 체격과 견봉의 크기에 맞춰 사용할 수 있다. 옆면에서 보면 금속판은 쇄골 모양에 맞춰 미리 $12^{\circ}$ 굴곡된 형태를 가지고 있 다. 본 연구에서는 $18 \mathrm{~mm}$ 깊이를 가진 4 hole 및 5 hole을 가진 금속판이 사용되었다.

\section{3. 수술 방법}

환자를 수술대위에 반좌위 (semifowler position)로 위치시킨 후 쇄골의 외측 $1 / 3$ 부위에서 쇄골을 따라 견 봉쇄골 관절 위로 지나는 약 $6 \sim 8 \mathrm{~cm}$ 의 피부 절개를 가하고 삼각근 및 승모근을 견봉 및 쇄골로부터 골막하 박리하여 견봉쇄골 관절의 외측 부위 및 견봉은 노출 시키지 않고 견봉쇄골 관절만을 노출시켰다.

관절낭과 상 견봉쇄골 인대는 보존하였으며 손상된 관절 디스크는 변연절제하였다. 이후 관절을 정복한 상 태에서 경피적 핀 (pin)고정을 하여 임시로 견봉쇄골 관절의 정복상태를 유지한 상태에서 금속판의 원위부에 있는 갈고리 (hook)를 견봉하 공간에 위치하도록 밀어 넣은 후 금속판의 나사구멍이 있는 근위부를 쇄골 모양 과 잘 맞게 위치 시켰다. 이때 환자의 해부학적 모양에 따라 금속판의 근위부 또는 원위부 갈고리를 구부려 견 봉하 공간 및 쇄골에 잘 맞도록 하였다. 환자에 따라 3 개 또는 4 개의 $3.5 \mathrm{~mm}$ 금속 나사로 금속판의 근위부 를 고정하였다. 금속나사 고정 시 비교적 피질골의 강 도가 약한 원위 쇄골부위 및 고령의 환자에서는 피질골 나사 대신 잠금 압박 나사 또는 해면골 나사를 사용하 였다 (Fig. 2).

금속판을 쇄골에 고정한 후 견봉쇄골 관절 인대 및 관절낭을 봉합하고 삼각근과 승모근을 근막과 함께 제 위치에 견고하게 봉합하였다. 오구쇄골인대는 봉합을 시행하지 않았다.

\section{4. 술후 관리}

수술 1 주 후 견관절 진자 운동을 시작하였고 술후 4 주까지 팔걸이를 착용 시켰으며 이후 점차적으로 운동 범위를 늘려 8 주까지 견관절 높이 아래에서 수동적, 능 동적 관절운동을 허용하였다. 이후 전범위 관절 운동을
허용하면서 전예에서 술후 $4 \sim 6$ 개월에 내고정물을 제거 하였다. 내고정물 제거 전 까지는 무리한 체중부하는 허용하지 않았다. 내고정물은 hook 금속판을 이용한 술식이 견봉쇄골 관절을 완전히 고정하지 않는 방법이 므로 연부조직의 충분히 치유될 때까지 기다려 제거하 였다. 내고정물의 제거 시 견봉쇄골 관절을 노출시키거 나 관절낭 또는 주위의 재생된 인대에 손상을 가하지 않게 하기 위해 이전 절개선의 내측 $1 / 3$ 만을 절개하여 고정나사를 제거하여 금속판을 들어 올려 고정물을 제 거하였다.

\section{5. 임상적 평가 방법}

술후 평가는 Constant-Murley 평가지표 ${ }^{5)}$ (Table 2) 를 이용하여 관절 기능을 점수화하였으며 금속판 제거 수술 후 4 주가 경과된 시점에서 외래 방문 시 시행하였 다. 평가 지표의 항목에 따라 통증 (15점), 일상생활 (20점), 운동범위 (40점), 근력 (25점)을 검사하였다. 이때 능동적 운동으로 운동범위를 평가하였으며 환자가 견봉쇄골 관절의 외상 및 수술이전에 환측 견관절에 기 존에 가지고 있던 질환에 대한 고려는 하지 않고 평가하 였다.

\section{6. 방사선학적 평가 방법}

건측과 비교하여 견봉쇄골 관절의 전위나 아탈구의

Table 2. The Constant-Murley score for acromioclavicular joint dislocation

\begin{tabular}{llr}
\hline \hline Distribution & & Score \\
\hline Pain & None & 15 \\
(15 points) & Mild & 10 \\
& Moderate & 5 \\
& Severe & 0 \\
Activities of daily living & Activity level(10 points) & \\
(20 points) & Full work & 4 \\
& Full recreation/sport & 4 \\
& Unaffected slip & 2 \\
& Positioning(10 points) & \\
& $\quad$ Up to waist & 2 \\
& Up to xiphoid & 4 \\
& $\quad$ Up to neck & 6 \\
& $\quad$ Up to top of head & 8 \\
Range of motion & $\quad$ Above head & 10 \\
(40 points) & Forward elevation & 10 \\
& Lateral elevation & 10 \\
Power & External rotation & 10 \\
(25 points) & Internal rotation & 10 \\
& Normal power is 25 pounds & 25 \\
& (proportionately less for less power)
\end{tabular}


소견을 보이지 않는 경우를 우수, 견봉쇄골 관절의 범 위내에서 $5 \mathrm{~mm}$ 이하의 전위를 보인 경우는 양호, 견 봉 쇄골 관절의 범위내에서 $5 \sim 10 \mathrm{~mm}$ 의 전위를 보인 경우를 보통, 견봉 쇄골 관절의 범위를 벗어나 전위가 재발하였던 경우를 불량으로 분류하였으며 ${ }^{11)}$ 우수와 양 호로 판정된 경우를 만족할 만한 회복을 보인 것으로 판정하였다. 또한 감염이나 금속나사못의 이완, 금속판 의 파열, 금속판 제거 후의 재탈구 등의 합병증 발생유 무를 관찰하였으며, 이러한 합병증이 발생한 예는 모두 불만족한 결과로 판정하였다.

\section{결 과}

수술 후의 모든 예에서 만족할 만한 회복을 보였으 며, Constant-Murley점수는 평균 90.5 (84 95)점 으로 우수하였다. 3 예에서 수술부위의 경미한 통증 및 삽입물로 인한 불편감을 호소하였으나 삽입물 제거 후 증상이 해소되었으며 일상생활에 지장을 줄 정도로 심 각한 통증이나 불편감이 남았던 예는 없었다.

모든 예에서 팔걸이를 이용하여 4 주간의 보호를 하며 견관절의 조기 운동을 시행하여, 수술 후 8주까지 관절 운동범위가 만족할만한 수준으로 회복되었다. 수술 후 4개월까지 관절 운동 범위가 원활하게 회복되지 않았던 2예에서는 금속판 제거 후 관절 운동범위가 정상으로 회복되었다.

방사선학적 평가 결과는 전예에서 우수하였고 수술직 후의 방사선 사진상 모든 예에서 쇄골의 수직 전위가 회복되었으며, 금속판을 제거한 후에 최종 추시 시 방 사선 사진상에서도 전예에서 수직전위가 관찰 되지 않 았다 (Fig. 3). 심부 감염, 금속나사의 이완, 금속판 파괴, 금속판 제거 후 재탈구 등의 합병증은 발생하지 않았다.

\section{고 찰}

견봉쇄골 관절의 탈구에 대한 치료 중 Rockwood 분
류 제 1,2 형의 손상은 대부분 보존적인 방법으로 치료 하고 있으나, 제 3형의 경우는 적절한 치료로서 수술적 방법과 보존적 방법에 대해 논란이 많지만 ${ }^{1.12 .16 .18)}$ 운동 선수나 육체노동에 종사하는 사람, 외관상 견봉쇄골 관 절의 변형을 받아들이지 못하는 사람은 수술적 치료의 대상이 된다.10). 본 연구에서는 제 3형 수상환자의 경 우 운동선수 1 명, 육체 노동자 4 명, 외관상 수술을 원 한 사람 2명이었다. Rockwood분류 제 4형, 5형, 6형 은 각각 원위 쇄골의 심한 후방전위, 육안상의 상방 전 위, 하방 전위로 인해 대부분의 저자들이 수술적 치료 권하고 있다 ${ }^{4)}$.

견봉쇄골 탈구의 수술기법은 크게 다섯 가지 범주로 나눌 수 있는데 첫째 쇄골과 오구돌기 사이의 고정술, 둘째 견봉쇄골 관절의 정복 및 고정, 셋째 이 두 가지 의 병합, 넷째 원위 쇄골부의 절제, 다섯째 근 이전술 등이 있다 ${ }^{2.11 .17)}$. 이들 중 Wolter 금속판을 이용한 견봉 쇄골 관절 수술은 견봉쇄골 관절 탈구의 수직 변형력을 중화하여 정복을 유지시키는 간접적 고정 방법으로 ${ }^{6}$ 관 절의 통합성을 회복할 수 있는 시점까지 비교적 장시간 관절의 정복을 견고하게 유지할 수 있고 조기 관절운동 을 허용할 수 있어 최근 견봉쇄골 관절 탈구 및 쇄골 외측단 골절까지 임상적 이용이 증가하고 있다. ${ }^{7.111}$. 저 자들은 AO hook 금속판을 사용하기 이전 2005년 10 월부터 2008년 1 월 까지 34예의 견봉쇄골 관절 탈구 환자를 Wolter 금속판을 이용하여 수술을 시행하였다. 그러나 이 수술법에서는 견봉의 갈고리 구멍의 위치를 정확히 선정하여야 하고, 갈고리 구멍의 확공과 이로 인한 통증 및 견봉 골절 등의 주요 합병증이 발생할 수 있으며 ${ }^{7.12)}$ 갈고리를 협소한 견봉하 공간을 지나 견봉의 구멍에 갈고리를 위치 시킬 때 견봉하 구조물의 자극을 피하고 피부 천공 및 자극을 피하기 위해 갈고리 길이 를 단축해야 하는 어려움을 경험할 수 있었다. 또한 비 보험 수가로 인하여 환자의 경제적 부담이 많아지는 문 제점도 있었다.

이에 저자들은 최근에 견봉을 뚫어서 고정하는 갈고 리가 없는 형태의 $\mathrm{AO}$ hook 금속판을 견봉쇄골 관절
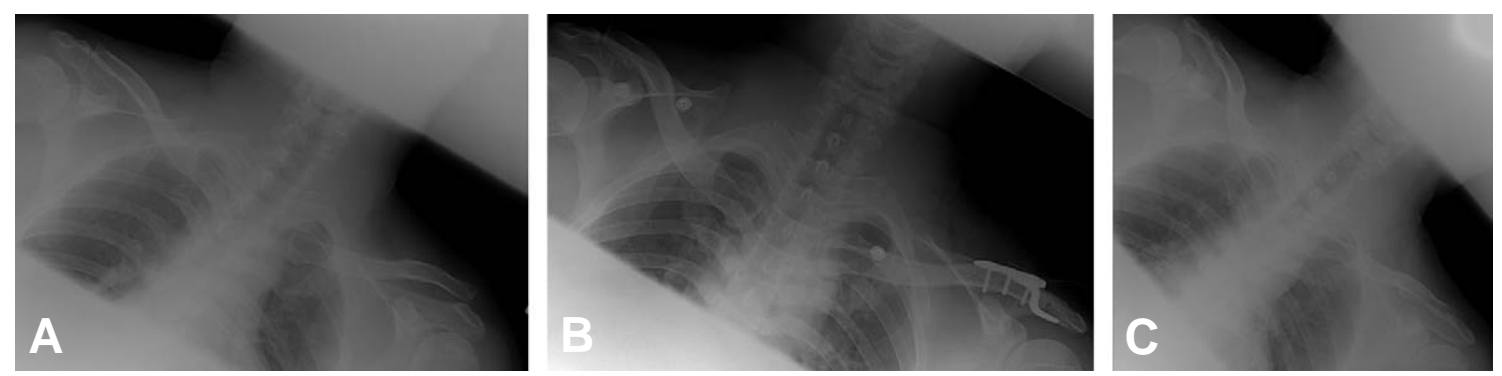

Fig. 3. A 45-year old male patient fell while playing soccer. (A) Complete acromioclavicular dislocation on the left side. (B) Ideal reduction was performed and it shows correct position of the implant. (C) Situation after plate removal: acromioclavicular joint and coracoclavicular interval were maintained well. 
탈구 수술에 사용하게 되었다. 이 금속판의 경우도 Wolter 금속판을 이용한 방법과 마찬가지로 견봉 쇄골 관절면에 직접적인 손상을 주지 않고 이 관절면 사이에 서 운동이 가능하여 수술 후 조기운동이 가능하다. 특 히 이 금속판의 가장 큰 특징은 Wolter 금속판 사용 시 견봉에 구멍을 내어 고정해야 했던 갈고리가 없이 견봉하 공간에 위치하는 부분의 첨부가 편평하다는 것 이다. 따라서 Wolter 금속판을 사용한 수술 시 중요한 성공적인 요소 중 하나인 견봉하 공간에서의 갈고리 구 멍의 위치를 정하는 과정 ${ }^{11}$ 은 본 금속판을 이용할 경우 고려할 필요가 없었다. 그러므로 견봉에 구멍을 내거 나, 피부 자극이나 천공을 염려하여 갈고리 첨부를 단 축하는 등의 과정도 필요하지 않고 전술한 견봉 골절이 나 확공에 의한 통증 등 Wolter 금속판 사용시 제기되 었던 문제점에 대해서 염려할 필요가 없고 술식도 상대 적으로 간단하였다. Koukakis 등흔 $\mathrm{AO}$ hook 금속 판을 사용할 경우 기초적인 금속판 고정술만 알면 성공 적으로 고정을 시행할 수 있으며, 특히 견봉쇄골 관절 탈구 환자를 자주 접하지 않는 의사들에게도 적합할 것 이라고 보고하였다. 저자들의 경우에도 Wolter 금속판 에 비해 견봉을 노출 시킬 필요가 없었고 견봉쇄골 관 절만 노출하여 더 작은 피부절개로도 용이하게 수술할 수 있었다. 하지만 견봉이나 쇄골 모양이 개인에 따라 차이가 있고 특히 견봉이 외측으로 기울어져 있는 환자 에서 견봉하 부위에 갈고리판을 넣고 위치 시킬 시 과 다한 정복이 되는 경우가 있어 갈고리판 및 금속판을 적절히 구부려 모양이 잘 맞도록 조작하는 과정은 이 금속판에서도 수술 시 중요한 과정이었다.

견봉쇄골 관절의 수직 안정성은 오구쇄골 인대에 의 해 유지 된다고 알려져 있으명, $\mathrm{AO}$ hook 금속판 제 거술 후에 이 관절의 수직 안정성은 오구쇄골 인대에 주로 의존한다는 주장도 있다 ${ }^{13)}$. 그러나 견봉쇄골 관절 손상에서 견봉쇄골 관절 재건술의 결과는 오구쇄골 인 대의 봉합여부에 영향을 받지 않는다는 연구들도 있으 며 ${ }^{614)} \mathrm{Luis}$ 등 $^{15)}$ 도 hook 금속판 사용시 오구쇄골 인대 의 봉합이 반드시 필요하지 않다고 보고하고 있어 저자 들도 수술 시 오구쇄골인대의 봉합은 시행하지 않았으 며 관절낭 및 견봉쇄골 인대, 삼각근과 승모근의 단단 봉합을 통하여 금속제거 후 견봉쇄골 관절의 안정성을 얻을 수 있었다. 견봉쇄골 관절의 동적 안정성에 기여 하는 삼각근과 승모근 기능에 대한 연구 ${ }^{14}$ 와 Wolter 금 속판을 이용한 수술 시 이 근육들의 복원의 중요성을 강조한 연구 ${ }^{11}, \mathrm{AO}$ hook 금속판 제거술 시 이 근육들 의 과다한 박리를 경계하는 연구 ${ }^{13)}$ 등을 바탕으로 본 연 구에서도 삼각근과 승모근을 견고하게 봉합하였으며, 금속판을 제거 후에도 견봉쇄골 관절의 수직 안정성을 유지하기 위해서는 이미 광범위하게 형성된 견봉쇄골
관절 및 오구쇄골 인대의 반흔조직을 가능한 한 손상시 키지 않는 것이 중요하다는 보고 ${ }^{13)}$ 가 있어 이를 배경으 로 술 후 $4 \sim 6$ 개월에 금속판 제거수술 시 이전 절개선 의 내측 $1 / 3$ 까지만 절개하여 이미 형성된 견봉쇄골 관 절의 반흔 조직과 복원된 인대에 손상을 주지 않도록 하였다.

본 연구에서 저자들은 $\mathrm{AO}$ hook 금속판을 견봉쇄골 관절 탈구의 수술적 치료에 사용하여 만족할 만한 결 과를 얻을 수 있었다. 하지만 Wolter 금속판에 비해 비교적 증례가 적고 금속제거술 후 추시 기간이 적은 한계점이 있어 향후 더 많은 환자를 대상으로 한 장기 추시 연구가 필요할 것으로 사료된다.

\section{결 론}

견봉쇄골 관절 탈구에 대한 여러가지 수술적 방법 중 에서 $\mathrm{AO}$ hook 금속판을 이용한 치료는 Wolter 금속 판을 이용한 치료의 장점을 유지하면서도 그 동안 이 금속판 사용시 제기되어왔던 문제점들을 해결할 수 있 는 장점도 가지고 있다고 판단되어 견봉쇄골 관절 탈구 의 치료로서 유용한 방법이라고 사료된다.

\section{REFERENCE}

1) Bae KC, Sohn SW, Cho CH, Jung SW: Surgical treatment of acromioclavicular dislocation-Comparison of modified Weaver-Dunn method and modified Phemister method. J Korean Shoulder Elbow Soc, 9: 155-161, 2006.

2) Bannister GC, Wallace WA, Stableforth PG, Hutson MA: The management of acute acromioclavicular dislocation. J Bone Joint Surg Br, 71: 848-850, 1989.

3) Bishop JY, Kaeding C: Treatment of the acute traumatic acromioclavicular separation. Sports Med Arthrosc Rev, 14: 237-245, 2006.

4) Chun JM, Kim SY, Choi JH, Kim TS, Kim KY: Surgical treatment of the acute acromioclavicular joint dislocation using a Wolter plate. J Korean Shoulder Elbow Soc, 37: 185-190, 2002.

5) Constant CR, Murley AH: A clinical method of functional assessment of the shoulder. Clin Orthop Relat Res, 214: 160-164, 1987.

6) Dumontier C, Sauter A, Man M, Apoil A: Acromioclavicular dislocations: treatment by coracoacromial ligamentoplasty. J Shoulder Elbow Surg, 4: 130-134, 1995.

7) Ernst S, Nikolaus S, Karl H, Andrea B: Repair of complete acromioclavicular separation using the acromioclavicular-hook plate. Clin Orthop Relat Res, 314: 134-142, 1995.

8) Fukuda K, Craig EV, An K-N, Cofield RH, Chao 
EY: Biomechanical study of the ligamentous system of the acromioclavicular joint. J Bone Joint Surg Am, 68: 434-440, 1986.

9) Fumiki M, Yasumasa S, Hiromoto I: Surgical treatment of comminuted fracture of the distal clavicle using Wolter clavicular plates. J Nippon Med Sch, 67: 32-34, 2000.

10) Galpin RD, Hawkins Rj, Grainger RW: A comparative analysis of operative versus nonoperative treatment of grade III acromioclavicular separation. Clin Orthop Relat Res, 193: 150-155, 1985.

11) Haberneck H, Weinstabl R, Schmid L, Fialka C: $A$ crook plate for treatment of acromioclavicular joint separation: indication, technique and result after one year. J Trauma, 35: 893-901, 1993.

12) Ko SH: Minimal incision Wolter plate fixation on the displaced lateral end fracture of the clavicle and the acromioclavicular dislocation. J Korean Shoulder Elbow Soc, 5: 23-28, 2002.

13) Koukakis A, Manouras A, Apostolou CD, et al.: Results using the AO hook plate for dislocations of the acromioclavicular joint. Expert Rev Med Devices, 5:
567-572, 2008.

14) Lizaur A, Marco L, Cebrian R: Acute dislocation of the acromioclavicular joint. Traumatic anatomy and the importance of deltoid and trapezius. J Bone Joint Surg Br, 76: 602-606, 1994.

15) Luis GE, Yong CK, Sigh DA, Sengupra S, Choon DS: Acromioclavicular joint dislocation: a comparative biomechanical study of the palmaris-longus tendon graft reconstruction with other augmentative methods in cadaveric models. J Orthop Surg, 2: 22-31, 2007.

16) Post M: Current concepts in the diagnosis and management of acromioclavicular dislocations. Clin Orthop Relat Res, 200: 234-247, 1985.

17) Rockwood CA, Young DC: Disorders of the acromioclavicular joint. In : Rockwood CA, Matsen FA ed. The shoulder. 1st ed, Philadelphia, WB Saunders Co: 413476, 1990.

18) Song HS, Choi NY, Han SK, et al.: Open reduction of acromioclavicular joint for the acromioclavicular joint dislocations. J Korean Shoulder Elbow Soc, 9: 189195, 2006.

\section{초 록}

목적: $\mathrm{AO}$ hook 금속판을 이용한 견봉쇄골 관절 완전 탈구의 치료 결과를 알아 보고자 하였다.

대상 및 방법: 2008년 2월부터 2009년 9월까지 AO hook 금속판를 이용하여 견봉쇄골 관절 탈 구로 수술 받은 환자 중 삽입물 제거한 10 례를 대상으로 하였다. 수술 후의 평가는 ConstantMurley score로써 임상적 평가를 시행하였으며, 금속판 제거 후 방사선 사진에서 견봉쇄골 관절 의 정복 상태 및 오구 쇄골 간격을 측정하였다.

결과: 전예에서 임상적으로나 방사선학적으로 만족할만한 결과를 얻었다. Constant-Murley점 수는 평균 90.5(84 95)점이었으며, 3예에서 수술부위에 경미한 통증 및 불편감을 호소하였지만 금속판 제거 후 증상은 해소되었다. 방사선학적으로도 전예에서 쇄골의 수직전위가 정복되었으며 감염, 금속판 파괴, 금속판 제거 후 재탈구 등의 합병증은 관찰 되지 않았다.

결론: $\mathrm{AO}$ hook 금속판을 이용한 견봉 쇄골 관절 탈구의 수술의 초기 추시 결과는 임상적, 방사 선학적으로 만족할 만한 결과를 보였다.

색인 단어 : 견봉쇄골 관절, 탈구, $\mathrm{AO}$ hook 금속판 